\title{
INTERMARRIAGE AND HOMOGAMY: Causes, Patterns, Trends
}

\author{
Matthijs Kalmijn \\ Department of Sociology, Utrecht University, Utrecht, The Netherlands; \\ e-mail: m.kalmijn@fsw.ruu.nl
}

KEY WORDS: marriage markets, marriage, mate selection, assortative mating, endogamy

\begin{abstract}
People have a tendency to marry within their social group or to marry a person who is close to them in status. Although many characteristics play a role in the choice of a spouse, sociologists have most often examined endogamy and homogamy with respect to race/ethnicity, religion, and socioeconomic status. I first give an overview of hypotheses on the causes of endogamy and homogamy. The various hypotheses that have been suggested in the literature can be distinguished as arguments about three more general factors: $(a)$ the preferences of marriage candidates for certain characteristics in a spouse, (b) the interference of "third parties" in the selection process, and (c) the constraints of the marriage market in which candidates are searching for a spouse. Second, I summarize empirical research by answering four questions: (a) To what extent are groups endogamous and how do groups differ in this respect? (b) How has endogamy changed over time? (c) Which factors are related to endogamy? (d) How do various dimensions of partner choice coincide? Third, I discuss strengths and weaknesses of past research. Strengths include the mass of descriptive work that has been done and the development of a multifaceted theoretical perspective which gives sociological theorizing an edge over psychological and economic theories of partner choice. Weaknesses include the lack of standardization of methods in describing patterns and trends and the relatively weak integration of empirical and theoretical work.
\end{abstract}




\section{INTRODUCTION}

Since the beginning of this century, sociologists have described patterns of partner choice and have tried to explain why people marry within their group (endogamy) and why people marry persons close in status (homogamy). The research literature can be divided into three traditions, depending on which type of characteristic is considered. Research on ethnic and racial intermarriage originated in immigrant countries such as the United States and is motivated by the question of whether the various nationality groups would integrate with one another and with the original population (Drachsler 1920; Wirth \& Goldhamer 1944). Research on religious intermarriage has been done both in and outside the United States and has been concerned with the extent to which churches control the life choices of their members and the degree to which religious involvement translates into the membership of "communal groups" (Kennedy 1944). Research on socioeconomic homogamy was developed by stratification researchers who used marriage patterns in conjunction with mobility patterns to describe how open stratification systems are (Glass 1954).

Although the underlying issues are diverse, one common theme is that all traditions characterize social differentiation by describing patterns of social interaction. Building on the Weberian notion of status group closure, students have argued that interaction between social groups provides a fundamental way to describe the group boundaries that make up the social structure. Because marriage is an intimate and often long-term relationship, intermarriage or heterogamy not only reveals the existence of interaction across group boundaries, it also shows that members of different groups accept each other as social equals. Intermarriage can thus be regarded as an intimate link between social groups; conversely, endogamy or homogamy can be regarded as a form of group closure.

Another common theme lies in the consequences of intermarriage. First, intermarriage decreases the salience of cultural distinctions in future generations because the children of mixed marriages are less likely to identify themselves with a single group. Although mixed couples may socialize their children into the culture of a single group, these children are less likely to identify with that group when intermarriage in society is common. Second, by intermarrying, individuals may lose the negative attitudes they have toward other groups. Although personal interaction between groups sometimes fosters conflicts by making economic and cultural differences more apparent, if the relationship is intimate, interaction gives people an opportunity to realize the individual variety among the members of another group and, in doing so, may ultimately weaken their prejudices and stereotypes. Because intermarriage often connects the social networks of the two spouses, this applies to a range of outgroup members and not just to the immediate partners. 
In short, what makes intermarriage sociologically relevant lies in its inherent dynamic: It is not just a reflection of the boundaries that currently separate groups in society, it also bears the potential of cultural and socioeconomic change. While marriage patterns are in this sense telling social indicators, they do not tell us everything. First, if members of two groups do not marry one another, it does not necessarily mean that both groups are closed. It takes two to marry, and if one group is closed while the other is open, endogamy may still prevail. Research on marriage is less informative in this respect than, for instance, research on individual racial prejudice. In a similar vein, homogamy tells a somewhat ambiguous story about the preferences and prejudices of status groups. Homogamy will occur if people prefer to marry into high-status groups, but it will also occur when people prefer to marry status-equals. In high-status groups, preferences for high-status spouses and preferences for status-equals are similar, but in lower-status groups, these are different.

Second, marriage patterns result from both preference and opportunity. Opportunity to marry within the group depends on many factors, such as residential segregation, the composition of local marriage markets, group size, and so on. As a result, endogamy does not necessarily point to a personally felt social distance toward a certain outgroup. Such preferences play a role, but to what extent they determine the actual choices people make is an empirical question. Marriage patterns simply tell us which groups interact with whom, and while this is an important piece of information, they do not tell us why.

A third and final limitation of marriage patterns lies in demographic trends. Declining marriage rates, the rise of cohabitation, and the increase in divorce suggest that it is not always valid to treat marriage patterns as indicators of differentiation in society as a whole. Some of these problems can be solved more easily than others. The rise of cohabitation poses no real problem because one can often include cohabiting couples in the analysis. Declining marriage rates are also less of a problem because they are largely the result of marriage delays; the vast majority of a given birth cohort eventually marries. The rise of divorce is more problematic, because intermarriage and divorce are often positively related. A high rate of ethnic intermarriage may point to open social groups, but if mixed marriages are more likely to break up, such a conclusion would need further study.

In the past decades, researchers have described patterns of intermarriage, examined individual variations in intermarriage, and assessed changes in intermarriage over time. In addition, both theoretical and empirical studies have developed hypotheses about why people marry within their group and why some do while others do not. Because such hypotheses are often not tested directly, I divide my review into a theoretical and an empirical section. The goal of the theoretical section is to review micro- and macro-level hypotheses about the causes of intermarriage and homogamy and to put these into a general theo- 
retical framework. The goal of the empirical section is to summarize patterns, variations, and trends in intermarriage. I focus on the three main sociological group characteristics (i.e. race and ethnicity, religion, and socioeconomic status), I limit myself to Western societies, and I discuss studies conducted in the last decade.

\section{THEORETICAL WORK ON INTERMARRIAGE AND HOMOGAMY}

Marriage patterns arise from the interplay between three social forces: the preferences of individuals for certain characteristics in a spouse, the influence of the social group of which they are members, and the constraints of the marriage market in which they are searching for a spouse (Kalmijn 1991b). Although these factors represent analytically distinct hypotheses, they have most often been regarded as complementary elements of a single theory, and that is what distinguishes the sociological perspective from economic or psychological theories on partner choice (e.g. Winch 1958).

\section{Preferences of Marriage Candidates}

To understand aggregate patterns of marriage selection, researchers use the concept of a marriage market. Unmarried men and women operate within a marriage market where each individual considers a set of potential spouses. Potential spouses are evaluated on the basis of the resources they have to offer and individuals compete with each other for the spouse they want most by offering their own resources in return. Several kinds of resources obviously play a role in the choice of a spouse, but sociologists have mostly focused on socioeconomic and cultural resources. When married, spouses pool these resources to produce family goods, such as economic well-being, status, social confirmation, and affection.

SOCIOECONOMIC RESOURCES Socioeconomic resources are defined as resources that produce economic well-being and status. Economic well-being is shared by the family members and status is granted to the family as a unit rather than to its individual members. As a result, the income and status of one spouse contribute to the income and status of the other by raising the income and status of the family. People maximize their income and status by searching for a spouse with attractive socioeconomic resources. The outcome of this competition is that the most attractive candidates select among themselves while the least attractive candidates have to rely on one another. Competition for socioeconomic resources on the marriage market thus leads to an aggregate pattern of homogamy.

The nature of this competition varies with the role women play in society. When marriage is based on the benefits that stem from the division of paid and 
domestic labor in the household, prevailing gender differences in earnings give men a comparative advantage in productive labor so that the wife's time is used more productively when it is spent on household labor. As a result, men and women exchange paid and domestic labor resources. Similar arguments have been made with regard to status and prestige. When the status of the family depends primarily on the occupation of the husband, there will be an exchange of male prestige and female qualities in other respects, such as class background, physical attractiveness, and cultural participation (Jacobs \& Furstenberg 1986; Stevens et al 1990; Uunk 1996).

Both types of exchange suggest that men, unlike women, do not compete among themselves for female socioeconomic resources in the marriage market. There are good reasons to believe that this has changed. An increasing number of married women participate in the labor market and married women's work is now less often motivated by temporary economic needs of the family. Several authors believe that these changes have made women's socioeconomic resources increasingly attractive to men. The wife's human capital may facilitate the husband's access to networks that are helpful in his career, her earnings may subsidize his human capital investments, and the economic security she provides may lessen his need to settle for short-term career benefits, thus increasing his opportunity to choose more attractive, long-term career objectives. Because female labor is now often the reflection of women's desire to work outside the home, rather than a reflection of the economic needs of the family, the wife's socioeconomic resources may also become increasingly important for the status of the family (Davis 1984).

CULTURAL RESOURCES While the importance of socioeconomic resources is based on a preference to marry a resourceful spouse, independent of one's own resources, the role of cultural resources is based on a preference to marry someone who is similar. Preferences for cultural similarity have been addressed most extensively in the social psychological literature on personal attraction (Byrne 1971). Similarity of values and opinions leads to mutual confirmation of each other's behavior and worldviews, similarity of taste is attractive because it enlarges opportunities to participate in joint activities, and similarity of knowledge creates a common basis for conversation, which enhances mutual understanding.

Although originally developed to explain attraction between strangers in day-to-day interaction, these notions have also been applied to marriage (DiMaggio \& Mohr 1985; Kalmijn 1994). Because cultural similarity leads to personal attraction, it is a prerequisite for getting involved with someone. Because of its instrumental effects, cultural similarity also encourages people to establish a long-term relationship. Since many activities in marriage are joint, such as the raising of children, the purchase of a house and other consumer durables, 
and the spending of leisure time, dissimilarity in taste would complicate these shared activities. More generally, people prefer to marry someone who has similar cultural resources because this enables them to develop a common lifestyle in marriage that produces social confirmation and affection.

PREFERENCES AND HOMOGAMY Preferences for socioeconomic and cultural resources do not by themselves translate into homogamy and endogamy with respect to social characteristics. Some authors argue that social characteristics are correlated with such resources, and that homogamy or endogamy is the unintended by-product of individual preferences for resources in a partner. This argument has often been made for educational homogamy, because education is not only strongly related to income and status, but also to taste, values, and lifestyles (Kalmijn 1991a). Similar arguments can be made for horizontally differentiated groups, such as ethnic groups, although in this case, endogamy is probably more the result of preferences for cultural similarity and not so much the result of competition for economically attractive spouses.

Other authors argue that social characteristics are more than simply correlates of the resources partners bring to the marriage market. Characteristics such as education, occupation, race, and ethnicity are also seen as badges that individuals wear to show others what kind of person they are. In this perspective, spouse selection is regarded as a filter process. In the first step, people develop a network of friends, acquaintances, and possibly marriage candidates with whom they share some objective social characteristic. In the second step, people find their spouse by interacting within these homogeneous networks. The second step is also the phase in which psychological characteristics come into play, but at that time, homogamy with respect to objective social characteristics is already insured (Murstein 1976).

\section{Third Parties}

A second hypothesis about why people marry within their group focuses on people who are not directly involved in the marriage. Because mixed marriages may threaten the internal cohesion and homogeneity of the group, "third parties" have an incentive to keep new generations from marrying exogamously. There are two ways in which third parties prevent exogamy: by group identification and by group sanctions.

GROUP IDENTIFICATION Children are typically brought up with a sense of group identification. Identification either takes the form of an awareness of a common social history, what is sometimes called a "sense of peoplehood" (Gordon 1964), or it can take the form of a more psychological sense of being different from others. The stronger such feelings of group identification, the more people have internalized norms of endogamy, and the more likely it is that they marry homogamously or endogamously. The notion of group identi- 
fication has been especially important for racial and ethnic groups, where norms of endogamy are believed to be firmly internalized (Merton 1941). Such norms, however, may also apply to other kinds of groups such as social classes and educational groups.

How strongly younger generations identify themselves with the group depends to a great extent on the homogeneity of the networks in which they are embedded. When adolescents live in neighborhoods that are homogeneous with respect to the social and cultural characteristics of their parents, they are more likely to develop a sense of belonging to that group. While residential segregation in urban areas hampers opportunities to intermarry directly, as is discussed later, it also reduced exogamy by intensifying feelings of group solidarity. Identification with the origin group is believed to be weakened by higher education. Owing to the emphasis on individual achievement and universalistic principles in higher education, the college-educated may be less likely to identify themselves with their social and cultural roots (Hwang et al 1995).

GROUP SANCTIONS Even if people have not internalized norms of endogamy, they may still refrain from marrying exogamously because of the sanctions third parties apply. The three most important examples of parties that sanction intermarriage are the family, the church, and the state. Although in Western societies parental control over children's marriage decisions is limited, there are still ways in which parents can interfere. They set up meetings with potential spouses, they play the role of matchmaker, they give advice and opinions about the candidates, and they may withdraw support in the early years of the child's marriage. Nevertheless, they do not have strong sanctions when children decide against their will.

Somewhat stronger sanctions are provided by the church. Both the Catholic church and various Protestant denominations have denounced interfaith marriages for centuries, although the nature and strength of their disapproval have changed over time. Religious institutions attempt to control intermarriage in part because they are competing for members. Religious intermarriage entails the risk of losing members and may weaken church attachment in future generations. If interfaith marriages occur anyway, it is not always in the interest of the church to apply sanctions because the competing church may accept the marriage and hence gain members. This helps explain why the Roman Catholic church, for example, has often accepted interfaith marriages on the condition that the children be raised as Catholics. Because of competing pressures, however, spouses in interfaith marriages often decide not to raise their children in a religious fashion. If this occurs, both religious institutions stand to lose strength in society.

The strongest sanctions against intermarriage have been provided by the state. Laws on racial intermarriage in the United States-abolished in 
1967-are a well-known example (Davis 1991). When slavery was abolished, the gradual decline in formal inequality of blacks and whites went hand-inhand with a growing anxiety about the social boundary between the races, and this anxiety was stronger when contacts were more intimate. Interracial dating and marriage were condemned with great vigor, and strong social norms emerged against interracial contacts with possible sexual undertones, such as interracial dancing and swimming. The emerging doctrine of no social equality was formalized in legislation that segregated the races in public facilities (Jim Crow laws) and legislation that controlled their sexual and marital contacts (antimiscegenation laws).

\section{Marriage Markets}

Endogamy and homogamy are not only governed by individual- and grouplevel factors, but also by structural arrangements. The chances to marry endogamously are higher the more often one meets people within the group and the more often one interacts with group members on a day-to-day basis. Contact opportunities are shaped by several structural arrangements. Some studies focus on the demographic composition of the population as a whole, other studies examine regional distributions of groups, and yet other studies analyze smaller, functional settings, such as the school and the workplace.

THE LOGIC OF NUMBERS When interaction occurs randomly, the chance that a woman in a certain group marries someone in her own group equals the proportion of men who are in that group. As a result, members of a small group will have lower chances of marrying endogamously than members of a larger group. The effect of group size implies that endogamy is negatively related to the degree of heterogeneity of a population (Blau \& Schwartz 1984). To explain this, one can think of two populations, each consisting of two groups. One population is heterogeneous and has $50 \%$ in each group (e.g. 100 in group A, 100 in group B), while the other is homogeneous and has $90 \%$ in one group and $10 \%$ in the other (e.g. 180 in group A, 20 in group B). Both populations have equal numbers of males and females in each group. In the heterogeneous population, the number of women expected to marry within the group will be $0.5 \times 50=25$ for $\mathrm{A}$ and $0.5 \times 50=25$ for $\mathrm{B}$, which boils down to $50 \%$ marrying within the group. In the homogeneous population, the number of women expected to marry within the group will be $0.9 \times 90=81$ for $A$ and $0.1 \times 10=1$ for $\mathrm{B}$, which boils down to $82 \%$. This shows that in a heterogeneous population, endogamy is lower than in a homogeneous population, provided that marriage is random.

THE GEOGRAPHY OF GROUPS The chance to encounter a member of one's own group does not depend on group size alone but also on the way a group is 
dispersed geographically (Blau \& Schwartz 1984). Groups that are concentrated in specific regions of the country generally have more opportunity to marry endogamously than groups that are not (Lieberson \& Waters 1988). Examples are common in the literature on ethnic groups, e.g. Asian-Americans in California, Jewish-Americans in New York City, or Catholics and Protestants separated in the southern and northern parts of the Netherlands. An additional reason why it is important to consider the geography of groups is that isolation may be correlated with group size. Smaller groups are often more isolated. Jewish-Americans, for example, may have partly overcome the constraints of their small group size through geographic concentration. They are a small group in a large country, but a large group in a small region.

Although relaxing the assumption of an even geographic distribution is more realistic, it also leads to new problems. If one controls for geographic segregation - by calculating endogamy rates for specific regions, for instance - one implicitly assumes that people base their decision to live in a given area on factors that are independent of ingroup preferences. This is not always realistic. For instance, there is much regional concentration of ItalianAmericans in the United States, but even though this can in part be attributed to their particular immigration history and occupational opportunities, the preferences of Italian-Americans play a role as well (Lieberson 1980). While it is difficult to make a precise distinction between preferences and constraints, it is generally true that the smaller the marriage market one studies, the more the structure of the market is affected by preferences and the less by constraints.

LOCAL MARRIAGE MARKETS Unmarried people do not just wander around a region looking for a spouse; they spend most of their life in small and functional places, such as neighborhoods, schools, workplaces, bars, and clubs. Such "local marriage markets" are often socially segregated, and that is why they are important for explaining marriage patterns. In the sociological literature, three local markets have been considered most frequently: the school, the neighborhood, and the workplace. Of these three, schools are considered the most efficient markets because they are homogeneous with respect to age and heterogeneous with respect to sex. Workplaces are considered less efficient, but increased participation of women in the labor market and declining occupational sex segregation suggest that this may have changed (Davis 1984). Although it has not often been studied where couples meet, a French study shows that the settings sociologists analyze are not the most common meeting places. Among young French couples, fewer than 5\% met in the neighborhood, fewer than $10 \%$ met at school, and just over $10 \%$ met at work (Bozon \& Heran 1989).

To clarify how local marriage markets affect homogamy, authors have looked at the composition of these markets with respect to social characteristics. What distinguishes the neighborhood from the school and the workplace 
is that it is homogeneous with respect to factors such as ethnicity, race, religion, and family background, i.e. characteristics transmitted by parents (Lieberson 1980). Schools are less homogeneous in ascribed characteristics, although there are exceptions, e.g. Catholic colleges and black colleges. At the same time, schools are not necessarily homogeneous with respect to educational attainment. Differences in ultimate educational attainment are larger in high schools, for example, than in universities, simply because the educational system works like a funnel, particularly in the United States (Mare 1991). In general, however, it is expected that colleges promote educational homogamy more than neighborhoods do, while neighborhoods promote ethnic endogamy and homogamy of family background more than schools. Whether workplaces encourage homogamy highly depends on the type of work, but on average, they probably do not encourage socioeconomic homogamy as much as schools.

\section{EMPIRICAL WORK ON INTERMARRIAGE AND HOMOGAMY}

Empirical work has addressed four questions: (a) To what extent are groups endogamous or homogamous, and how do groups differ in these respects? (b) How have endogamy and homogamy changed over time? (c) Which factors are related to endogamy and homogamy, and in particular, what is the role of gender, education, and geographic regions and local marriage markets? $(d)$ How do various dimensions of partner choice coincide? Before I summarize the main findings, I discuss how researchers have tackled these issues methodologically.

\section{Measures and Models}

Intermarriage can be calculated for the stock of marriages at a given point in time (prevalence measures) or for people who marry in a given period of time (incidence measures). Incidence measures are generally preferable, in particular if one analyzes trends. If the stock of marriages is used, one can analyze characteristics at the time of survey or characteristics at the time of marriage. The latter measures are more suitable than the former because some characteristics change after marriage. Because partners may become more alike during marriage - they may switch faith, for example, or influence each other's occupational career - current measures of homogamy tend to be biased upwardly. To describe intermarriage, various measures have been used. To explain these, it is helpful to consider the following marriage table.

MEASURES The most general measure is the percentage of couples intermarrying: $\left(\mathrm{C}_{\mathrm{BA}}+\mathrm{C}_{\mathrm{AB}}\right) / \mathrm{N}$. When calculating group-specific measures, it makes a difference if one considers couples or individuals. The percentage of A-type 


\begin{tabular}{llccc}
\hline & & \multicolumn{3}{c}{ FEMALES } \\
& & Group A & Group B & Total married \\
\multirow{4}{*}{ MALES } & Group A & $\mathrm{C}_{\mathrm{AA}}$ & $\mathrm{C}_{\mathrm{AB}}$ & $\mathrm{M}_{\mathrm{A}}$ \\
& Group B & $\mathrm{C}_{\mathrm{BA}}$ & $\mathrm{C}_{\mathrm{BB}}$ & $\mathrm{M}_{\mathrm{B}}$ \\
& Total married & $\mathrm{F}_{\mathrm{A}}$ & $\mathrm{F}_{\mathrm{B}}$ & $\mathrm{N}$ \\
\hline
\end{tabular}

couples intermarrying is $\left(\mathrm{C}_{\mathrm{BA}}+\mathrm{C}_{\mathrm{AB}}\right) /\left(\mathrm{C}_{\mathrm{BA}}+\mathrm{C}_{\mathrm{AB}}+\mathrm{C}_{\mathrm{AA}}\right)$, while the percentage of A-type married persons intermarrying is $\mathrm{C}_{\mathrm{AB}} / \mathrm{M}_{\mathrm{A}}$ for males and $\mathrm{C}_{\mathrm{BA}} / \mathrm{F}_{\mathrm{A}}$ for females. While percentages are simple and informative measures to describe intermarriage, they provide little information about the strength of endogamy because they lack a reference point. If $40 \%$ of a group marries endogamously, is this evidence for a preference to marry within rather than outside the group? Percentages are also less useful for comparing groups because when selection is random, small groups are less likely to marry within their group than large groups.

These problems are overcome by a more recent measure, the odds ratio. The odds ratio is defined as the odds that an A-type male marries an A-type female (rather than a B-type female), divided by the odds that a B-type male marries an A-type female, i.e. $\left(\mathrm{C}_{\mathrm{AA}} / \mathrm{C}_{\mathrm{AB}}\right) /\left(\mathrm{C}_{\mathrm{BA}} / \mathrm{C}_{\mathrm{BB}}\right)$. The odds ratio for women is equivalent, i.e. $\left(\mathrm{C}_{\mathrm{AA}} / \mathrm{C}_{\mathrm{BA}}\right) /\left(\mathrm{C}_{\mathrm{AB}} / \mathrm{C}_{\mathrm{BB}}\right)$. If there are more than two groups in the marriage table, one can calculate odds ratios for each group separately. If $\mathrm{C}_{\mathrm{AX}}$ and $\mathrm{CX}_{\mathrm{XA}}$ are marriages of A-type males and females with all other groups, and $\mathrm{CXX}$ are marriages that do not involve A-type males or females, the odds ratio can be defined as $\left(\mathrm{C}_{\mathrm{AA}} / \mathrm{C}_{\mathrm{AX}}\right) /\left(\mathrm{CX}_{\mathrm{XA}} / \mathrm{CXX}_{\mathrm{XX}}\right)$. Odds ratios have two important advantages. First, they provide a reference point: Odds ratios greater than one indicate that there is more endogamy than one would expect, and the larger the ratio, the greater the degree of endogamy. Second, odds ratios are useful for comparing endogamy across groups because they are independent of the relative sizes of the groups in the marriage table.

A disadvantage of the measures discussed above is that they are based on the married or marrying population. A measure of intermarriage that takes into account that not everyone marries is the intermarriage index $\mathrm{Z}$, which is based on so-called harmonic mean models developed by Schoen (1988). If MP and FP refer to the total number of males and females in the respective groups (married and unmarried), $\mathrm{Z}$ is defined as $\left(\mathrm{C}_{\mathrm{AB}} / \mathrm{MPA}+\mathrm{C}_{\mathrm{BA}} / \mathrm{FPA}_{\mathrm{PA}}+\mathrm{C}_{\mathrm{BA}} / \mathrm{MPB}_{\mathrm{PB}}+\mathrm{C}_{\mathrm{AB}} /\right.$ $\left.\mathrm{F}_{\mathrm{PB}}\right) /\left(\mathrm{M}_{\mathrm{A}} / \mathrm{MPA}_{\mathrm{PA}}+\mathrm{M}_{\mathrm{B}} / \mathrm{MPB}_{\mathrm{PB}}+\mathrm{F}_{\mathrm{A}} / \mathrm{F}_{\mathrm{PA}}+\mathrm{F}_{\mathrm{B}} / \mathrm{F}_{\mathrm{PB}}\right)$. This intermarriage index ranges from zero for minimum intermarriage to one for maximum intermarriage. When selection is random, the index takes the value of 0.5 (Schoen 1988).

Percentages, odds ratios, and the intermarriage index can be applied to both ordered and nonordered characteristics. For ordered characteristics, another common measure is the Pearsonian correlation between spouses' traits. A positive correlation means that high-status men marry higher-status women 
than low-status men; it does not necessarily mean that people marry within their group. The correlation between the ages of husband and wife, for example, is strongly positive, even though most men marry somewhat younger women.

MODELS Second to measures of intermarriage, loglinear models have been used to describe patterns of marriage selection. These models assume that the expected counts in the marriage table are a multiplicative function of sample size, the number of males in a group, the number of females in a group, and an interaction parameter, which measures marriage selection independent of the marginal row and column distributions. Many ways to model the interaction parameter exist, but most authors present parameters for the tendency to marry within the group (endogamy) and parameters for the tendency to avoid intermarrying when controlling for the tendency to marry within the group (intermarriage). The latter parameters are often equivalent to odds ratios and have been described by the metaphors of distances or boundaries between groups (Mare 1991; Kalmijn 1991b). When characteristics are ordered, loglinear models also provide single measures of association that are comparable to correlations but independent of the marginal distributions, i.e. uniform association models (Hout 1982). When characteristics are not ordered, special types of loglinear models exist that provide measures of the distances between groups as revealed by the marriage frequencies in the table, i.e. logmultiplicative models (Johnson 1980; Kalmijn 1993a).

\section{Patterns of Intermarriage and Homogamy}

In describing patterns of intermarriage and homogamy, researchers have addressed three questions: (a) To what extent do subgroups marry endogamously? (b) If subgroups marry out, with what groups are they most likely to intermarry? and (c) How do subgroups compare in their degree of endogamy?

RACE/ETHNICITY Most American studies of ethnic intermarriage analyze data from the perspective of the minority group and focus on specific types of subgroups. Several decades ago, interest largely focused on European immigrant subgroups and their children. More recently, new immigrant subgroups such as Asian- and Hispanic-Americans are being studied, though there is a resurgent interest in the descendants of the older immigrants, sometimes referred to as white ethnic groups. Intermarriage of blacks has always been studied frequently. Research on intermarriage of American Indians, in contrast, is scarce.

Recent national estimates of the percentage of persons who are married endogamously vary around $95 \%$ for blacks (Sweet \& Bumpass 1987), $75 \%$ for Asian subgroups (Lee \& Yamanaka 1990), 65\% for Hispanic subgroups (U.S. Bureau of the Census 1985), 45\% for American Indians (Snipp 1989), and 
$25 \%$ for (unmixed) European subgroups (Alba \& Golden 1986). Although these percentages are high, they do not indicate whether groups are endogamous. Loglinear models and harmonic mean analyses are more informative in this respect and show that virtually all ethnic subgroups marry within their group more often than can be expected under random mating (Jiobu 1988; Schoen \& Thomas 1989; Sandefur \& McKinnell 1986; Alba \& Golden 1986).

A low degree of endogamy does not necessarily imply integration; this also depends on patterns of outmarriage. When Hispanic subgroups marry exogamously, for example, they often marry with other Hispanic subgroups and hence keep a distance from the non-Hispanic white majority (Gurak \& Fitzpatrick 1982). Asian-Americans who marry out, in contrast, rarely marry other Asian subgroups and instead marry with whites (Lee \& Yamanaka 1990). Intermarriage between European subgroups also reveals meaningful patterns. In the first half of this century, marriage selection was characterized by a large distance between Western and Northern Europeans on the one hand and Southern, Central, and Eastern Europeans on the other (Pagnini \& Morgan 1990; Kalmijn 1993a). This finding has been interpreted as evidence of a boundary between the "old" and "new" European immigrants to the United States.

How do subgroups compare in their degree of endogamy? Unfortunately, most studies focus on one type of subgroup at a time without analyzing other types. A broader focus is provided by Lieberson and Water, who present a list of odds ratios for more than 20 groups (1988). European subgroups and American Indians appear to have the lowest rates of endogamy, Hispanic and Asian subgroups have intermediate levels of endogamy, and blacks have the highest rates. There are also differences among European subgroups-for instance, endogamy is lower for "old" than for "new" European groups-but these are small when considering the range in the list. The main conclusion of Lieberson and Water's analysis is that groups who are more recent to the host society have higher degrees of closure, a regularity that fits well into assimilation theories. Blacks are the prime exception to this pattern. A similar relationship between the newness of a group and its level of endogamy is found in Australia (Jones \& Luijkx 1996).

RELIGION Religious intermarriage has primarily been studied in religiously heterogeneous societies. Some authors use current religious affiliation to measure intermarriage, while others use the religion in which spouses were raised. Endogamy is higher when current affiliation is used, because spouses often switch faith or lose their religion after entering a mixed marriage (Glenn 1982). Estimates for the United States that use parental religion show that in the late 1970 s, $62 \%$ of Catholics were married within their group, $84 \%$ of Protestants were married endogamously, and $80 \%$ of Jews were married endoga- 
mously (Glenn 1982). Loglinear analyses further show that both Catholics and Protestants have a tendency to marry within rather than outside their group; this is found in the United States (Kalmijn 1991b), the Netherlands (Hendrickx et al 1991), Germany (Hendrickx et al 1994), Australia (Hayes 1991), and Switzerland (Schoen \& Thomas 1990). Comparisons between countries using odds ratios show that endogamy is strongest in Ireland and Northern Ireland, as one would expect, and that Catholic endogamy is stronger in the United States than in most European countries (Klein \& Wunder 1996).

Which religious groups are most endogamous? Loglinear analyses in the United States indicate that Catholics are somewhat more closed than Protestants (Johnson 1980). Loglinear analyses have not included Jews, but it is safe to say that American Jews are more endogamous than Catholics because their intermarriage percentage is comparable to that of Catholics, while they are a much smaller group. Detailed loglinear analyses of Protestant denominations show that more-conservative Protestant denominations, such as the Rereformed in the Netherlands (Hendrickx et al 1994) and Baptists in the United States and Australia (Johnson 1980; Hayes 1991) are more endogamous than liberal denominations. These findings are consistent with the notion of thirdparty control: Denominations and religions that are more traditional in religious doctrine and have higher degrees of church involvement among their members also have the highest degree of endogamy.

When analyzing marriages between religious groups, authors have used the concept of social distance and have developed loglinear models providing such measures. In the United States, such analyses point to the following order of groups: Baptists, Methodists, liberal Protestants, Lutherans, and Catholics (Johnson 1980). These distances have been interpreted in terms of ritual and regional dimensions. Groups on the left side of the continuum are more democratic in their organization, have less detailed prescriptions of ritual, and emphasize more spontaneous forms of worshiping than groups on the right side of the continuum. Regional patterns play a role here as well. Baptists and Methodists are concentrated in the South, for example, while Catholics are concentrated in the Northeast.

SOCIOECONOMIC STATUS The literature on socioeconomic homogamy can be distinguished into studies of ascribed status and studies of achieved status. Ascribed status positions are measured by the occupational class of the father and the father-in-law. Achieved status positions are measured by education and occupation. Education is used more often because it is a convenient status indicator of women and changes little after marriage. In most countries, educational homogamy is quite strong (about 0.55 ), occupational homogamy is somewhat weaker (about 0.40 ), while the correlation between husbands' and wives' class origins is the weakest, about 0.30 (Kalmijn 1991a; Uunk 1996). 
Loglinear analyses provide additional insights in the association between partners' status positions. Such analyses first show that people marry within rather than outside socioeconomic groups, although some groups are more closed than others. Groups at the top and the bottom of the educational hierarchy are more closed than groups in the middle (Uunk et al 1996; Hendrickx 1994). These tendencies may be due to the role of opportunity: If people at the bottom prefer to marry out, they can only choose higher groups and if people at the top prefer to marry out, they can only choose lower groups. People from farm background have an exceptionally high rate of endogamy, a finding that can probably be explained in terms of the social and geographic isolation of the rural population (Kalmijn 1991a; Uunk et al 1996; Jones \& Davis 1988).

Next to a tendency to marry within the group, there is a tendency for marriage to become less common the farther away the two status positions are. Some status boundaries are harder to cross than others, however. For education, the strongest boundary is that between college graduates and lessereducated persons (Mare 1991; Kalmijn 1991a). A common interpretation of this finding is that colleges function as local marriage markets that are physically separated from settings in which lesser-educated persons are involved. Patterns of occupational homogamy, like patterns of intergenerational occupational mobility, are dominated by the line that divides blue-collar and whitecollar occupations (Hout 1982; Hayes 1993). More detailed analyses of occupational homogamy have shown that there is more homogamy with respect to the cultural status of occupations than with respect to the economic status of occupations (Kalmijn 1994). This suggests that preferences for cultural similarity are stronger than preferences for economically attractive spouses.

\section{Trends in Intermarriage and Homogamy}

Trends have been analyzed in three ways. (a) Some researchers compare marriage or birth cohorts at a single point in time. Such synthetic cohort studies are potentially biased because older cohorts have been married longer than younger cohorts. Cohorts differ in their rate of attrition, and this attrition may be selective because the likelihood of divorce is inversely related to homogamy. (b) Other studies compare the stock of intact marriages at different points in time. This design has the disadvantage of containing much overlap of marriages in the points of comparison, which leads to an underestimation of linear trends. (c) Others, finally, compare recently formed marriages in different periods, either through annual marriage licenses or through comparisons of newlyweds in multiple surveys or censuses. This method is most suitable for analyzing trends because it gives a picture of the changing incidence of intermarriage. 
RACE/ETHNICITY Analyses of marriage records generally reveal an increase in intermarriage of new ethnic groups in the last decades; this applies to Hispanic intermarriage in New York City (Gilbertson et al 1996), to Asian intermarriage in Hawaii (Schoen \& Thomas 1989), and to Asian intermarriage of males_-not females - in New York City (Sung 1990). The trend in blackwhite intermarriage has been documented for a longer time period and in more states. Annual marriage records in 33 states reveal that black-white intermarriage has increased significantly in both northern and southern states since the legal ban on intermarriage was lifted, although it remains exceptionally low (Kalmijn 1993b). Comparisons of the 1980 and 1990 American censuses confirm this conclusion (Qian 1997). Ethnic characteristics that are not included in marriage licenses have primarily been analyzed through synthetic cohort analyses. Such studies reveal growing outmarriage across birth cohorts for European-American groups (Alba \& Golden 1986; Lieberson \& Waters 1988), for American Indians (Eschbach 1995), and for ethnic groups in Australia (Jones \& Luijkx 1996).

The decline in ethnic endogamy has typically been interpreted from an assimilation perspective: Through generational replacement, national origin groups gradually integrate in the host society. Consistent with this perspective, most analyses find that the children of immigrants marry out more often than the immigrants themselves (Gilbertson et al 1996; Lee \& Yamanaka 1990; Alba 1976). Because trends also occur within generations of immigrants, individual assimilation to the host society is not a sufficient explanation (Gilbertson et al 1996; Sung 1990). An additional interpretation is that assimilation is a process at the macro level: When more and more members of an ethnic group are of the second or third generation-when an ethnic group becomes "older" - all generations find it easier to adapt to the host society. Another interpretation is more general in nature and points to the weakening influence of third parties in marriage choice and the declining importance of ascription as a basis of evaluating other people.

RELIGION In the United States, trends in religious homogamy have primarily been assessed through surveys, largely because few places report religion on their marriage licenses and because the census is not allowed to ask questions on religious affiliation. By analyzing national surveys conducted between 1955 and 1989 and using a design that separates the effects of period and duration of marriage, Kalmijn (1991b) shows that intermarriage between Catholics and Protestants has increased in a linear fashion between 1920 and 1980 . Trends in intermarriage between Jews and non-Jews have been documented by comparing subsequent surveys (Lazerwitz 1995) and by comparing marriage cohorts within a single survey (Kosmin et al 1991). Both types of analyses show that Jewish-Gentile intermarriage has increased considerably over the 
last decades. An exception to these trends are conservative Christian groups, who appeared to have stable endogamy rates over time (McCutcheon 1988).

In many other Western societies, questions on religion are included in marriage records so that long-term trends can be documented there more easily. A loglinear trend analysis of annual Dutch marriage records since the 1930s shows that religious endogamy of Catholics and the conservative ReReformed Protestants has declined (Hendrickx et al 1991). The more liberal Dutch Reformed Protestants experienced no decline, but they had low levels of endogamy to begin with. Marriage records in Switzerland (Schoen \& Thomas 1990) and Germany (Hendrickx et al 1994) also reveal a decline in the level of endogamy of Catholics and Protestants. That the boundaries between religious groups in Europe and the United States have weakened during the twentieth century is consistent with the notion of declining third-party control and matches long-term processes such as secularization and depillarization.

SOCIOECONOMIC STATUS Trends in socioeconomic homogamy are most frequently studied by analyzing class background and education. In most industrialized countries, there has been a decline in the importance of social background for marriage choice. This has been found for the United States (Kalmijn 1991a), the Netherlands (Uunk 1996), Hungary (Uunk et al 1996), and France (Forsé \& Chauvel 1995). The most common interpretation of this trend lies in the role of third parties and opportunity. Young adults have become increasingly independent of parents so that parents have less direct or indirect control over the choices their children make. People also spend more time in school settings, which are more heterogeneous with respect to social class background than the parental neighborhood.

Trends in educational homogamy do not point in one direction. A loglinear analysis of 18 postwar industrial nations by Ultee \& Luijkx (1990) reveals that five countries experienced a decline in educational homogamy, three countries experienced an increase, while the remaining ten revealed no meaningful trend. Country-specific loglinear analyses also reveal a mixed pattern, although they do not reveal a decline in homogamy: $(a)$ a strong increase in the United States (Mare 1991; Kalmijn 1991a), Hungary (Uunk et al 1996), and Germany (Blossfeld \& Timm 1997); (b) a slight increase in the Netherlands (Hendrickx 1994); and (c) stability in Australia (Jones 1987) and France (Forsé \& Chauvel 1995).

Several hypotheses have been suggested to explain these trends. Some authors argue that opportunities for making a match on education have increased. People marry later and spend more time in school, but the time interval between leaving school and marriage has narrowed. As a result, it is now more likely that unmarried people, especially the college educated, meet their spouse in school (Mare 1991). Others point to the role of preferences. Educa- 
tion has become an increasingly important proxy for both cultural taste and socioeconomic success, and competition among men for socioeconomic resources in women may have increased (Kalmijn 1991a; Schoen \& Wooldredge 1989). There are also hypotheses predicting a decrease in educational homogamy. Some authors argue that marriage choice has become increasingly based on emotional or affective considerations. Because romantic considerations often overrule status concerns, one would expect a decline in all forms of status homogamy (Ultee \& Luijkx 1990).

An attempt to reconcile these hypotheses is made by Smits et al (1998), who argue that educational homogamy will initially increase with levels of industrialization because in this phase, education becomes the dominant criterion for socioeconomic success and cultural norms and values. Romantic considerations and individualism gain importance in later stages of the industrialization process when high standards of living are guaranteed for everyone. As a result, educational homogamy will first increase with levels of industrialization, but will eventually decrease. A comparison of 64 countries provides indirect support for this claim: The relationship between educational homogamy and the level of industrialization follows an inverted "U."

\section{Variations in Intermarriage and Homogamy}

Next to describing patterns and trends, authors have analyzed variations in intermarriage and have examined what factors contribute to outmarriage. Recurring themes in the literature are differences by sex, by education, and by region. Although these factors are generally studied in an exploratory fashion, they also give us clues about the causes of endogamy.

SEX DIFFERENCES Sex differences have most often been studied in the literature on racial and ethnic intermarriage. Studies on black-white intermarriage in the United States consistently show that black men marry whites more often than black women (Kalmijn 1993b; Schoen \& Wooldredge 1989). A traditional interpretation of this finding is that minority men are able to compensate for their lower "ethnic prestige" by offering white women a high occupational status or income. Although in principle one could reverse the exchange-highstatus minority women could marry white men of lower status - under conditions of traditional sex-roles, this type of marriage is believed to be uncommon because the status of the family is largely dependent on the status of the husband.

Although the interpretation is plausible, findings for other ethnic groups provide a counterpoint. Asian-American women, for example, and in particular Japanese-American women, marry whites more often than their male counterparts (Sung 1990). A speculative interpretation of this exception is that Asian-American women are attractive marriage candidates for white men be- 
cause of their physical appearance and presumed acceptance of more traditional power relationships in marriage. A more-plausible interpretation lies in the role of opportunity: the presence of American soldiers in Japan and Korea. A recent analysis shows that excluding such war brides leads to a substantial reduction in the sex differential in Asian-American intermarriage (JJ Jacobs \& T Labov, unpublished manuscript).

Sex differences have also been studied in the analysis of socioeconomic homogamy. A common finding is that highly educated men and men in professional and technical occupations marry down more often than up (Mare 1991; Kalmijn 1994). Laymen generally interpret downmarrying as evidence of a reluctance on the part of men to marry high-status women, but most of the asymmetry is due to differences in the composition of men's and women's characteristics. On average, women have traditionally been less educated and less often have had high-status occupations than men. Once such differences are taken into account through loglinear analyses, researchers generally find little evidence of asymmetry (Mare 1991). Similar conclusions apply to trends: Educational downmarrying among men has become less common, but this is largely due to the increased educational attainment of women (Mare 1991).

EDUCATIONAL EFFECTS Another frequently examined factor in intermarriage is education. Many studies have found that more highly-educated members of ethnic or racial minority groups marry exogamously more often than their lesser-educated peers. This applies to white ethnic groups (Lieberson \& Waters 1988), blacks (Kalmijn 1993b; Schoen \& Wooldredge 1989), and American Indians (Sandefur \& McKinnell 1986). Less consistent evidence is found for outmarriage of Asian-Americans (Hwang et al 1995; Wong 1989; Schoen \& Thomas 1989).

Educational effects have been interpreted in terms of both opportunity and preference. The former interpretation states that better educated minority members are more often exposed to settings such as colleges and high-status occupations where they form a relatively smaller group than in the population at large. Another interpretation states that more highly educated persons - of both majority and minority groups - have a more individualistic attitude, are less attached to their family and community of origin, and have a more universalistic view on life than lesser-educated persons. As a result, they would find ascribed characteristics less relevant in deciding whom to marry.

DIFFERENCES BETWEEN REGIONS AND SETTINGS Virtually all studies find large regional differences in intermarriage. Asian-Americans marry out less often in California, where they are concentrated, than in the rest of the United States (Wong 1989), Indian-Americans are more endogamous in so-called Indian States (Sandefur \& McKinnell 1986), and blacks marry more endoga- 
mously in states where the percentage of blacks in the population is larger, a relationship that is observed both in and outside the South (Kalmijn 1993b). Such patterns undoubtedly point to the role of opportunity: The smaller the group, the more difficult it is to marry within the group. Hypotheses about group size and its corollary, heterogeneity, have also been examined by analyzing (Standard) Metropolitan Statistical Areas [(S)MSAs) or states through correlational analyses. These studies find that relative group size is negatively correlated with black outmarriage and ethnic outmarriage; similarly, racial, ethnic, and occupational heterogeneity have positive effects on the respective types of intermarriage (Blau et al 1982; Hwang et al 1994).

The role of opportunity has also been analyzed by considering local marriage markets. In a classic study, Ramsøy (1966) analyzed marriage licenses in a Norwegian city and found that husbands and wives lived close to each other before marriage, and in fact closer than one would expect under conditions of random mating in a city. While this confirms that neighborhoods are marriage markets, Ramsøy also showed that people who lived close to one another before marriage did not marry more homogamously with respect to occupation than people who lived far apart. Hence, it appeared that the neighborhood did not by itself promote occupational homogamy. Ramsøy's analysis was criticized on methodological grounds by Peach (1974), but later, more elaborate analyses of newlyweds in a New Zealand city by Morgan (1981) found no clear link between spatial and status proximity either. Analyses of ethnic endogamy yield a more promising conclusion. Anderson \& Saenz (1994), for example, find that MSAs in which Mexican-Americans are residentially segregated from non-Hispanic whites have lower degrees of Mexican-American outmarriage, even when other group characteristics such as mean educational level are controlled for.

The school is another local marriage market, but its role in promoting educational homogamy has only been studied indirectly. Mare (1991) found that people who marry closer to finishing school, or while in school, marry people who are more similar in education than people who marry long after finishing school. This relationship was found to be present only for higher levels of education. A similar relationship is found in Germany, although there, a decline in educational homogamy is only observed when comparing couples who married a few years after leaving school with couples who married much later (Blossfeld \& Timm 1997). These findings provide indirect evidence that schools function as marriage markets that favor educational homogamy. Schools, and in particular colleges, are educationally homogeneous, while the settings people face when they search for a partner at a later stage, such as work settings and public places, tend to be less homogeneous. Further evidence on the role of schools is provided by Uunk \& Kalmijn (1996), who show that the college-educated in the Netherlands have a tendency to marry someone who 
has the same college major. In the Netherlands, fields of study can be regarded as local marriage markets within the university because students choose a major when they first enroll and do not follow courses in other fields.

\section{Multiple Dimensions}

Most early studies analyzed a single sociological characteristic at a time or analyzed several characteristics one-by-one. Since partners choose each other on the basis of multiple characteristics, it is important to analyze more than one factor in marriage choice. In the last decades, several such multidimensional analyses have been done, although most are limited to two dimensions. Research on multiple dimensions has been guided by two hypotheses: the byproduct hypothesis and the exchange hypothesis.

BY-PRODUCT HYPOTHESES There is a considerable overlap between social groups in society. Ethnic groups, for example, differ in educational level, religion and ethnicity often coincide, and education and social background are correlated. Because the various social dimensions on which individuals select one another are correlated, and because people are believed to take all these dimensions into account when choosing a spouse, the question arises if and to what extent homogamy in one group dimension is the by-product of selection in another group dimension.

An early attempt to examine this issue empirically was done by Warren (1966; see also Blau and Duncan 1967:354-59), who showed that the correlation between the spouses' fathers' occupations is reduced substantially when controlling for spouses' education. This result led Warren to conclude that social class homogamy is largely a by-product of educational homogamy. More recent analyses confirm this and show in addition that educational homogamy is in part a by-product of matching of social origins (Kalmijn 1991a; Uunk 1996). Hence, both forms of homogamy appear to be weaker when a multidimensional analysis is used, although even then, educational homogamy remains stronger than homogamy of social origins.

The by-product hypothesis has also been a theme in the study of ethnic intermarriage. A classic study of New Haven in the first half of this century by Kennedy (1944) showed that intermarriage is more common between groups who have the same faith, such as between Italians and Poles on the one hand (both largely Catholic) and between Hungarians and Russians on the other (both largely Jewish). Kennedy used the now classic term "triple melting pot" to describe this pattern. Kennedy's triple melting pot confirms the by-product hypothesis because it reveals that marriage boundaries between certain ethnic groups are in part the result of differences with respect to religion. Recent, more sophisticated loglinear analyses confirm that there are strong marriage boundaries between ethnic groups who have a dissimilar faith (Alba \& Golden 
1986), but no studies have simultaneously analyzed individual ethnic and religious characteristics of husbands and wives.

EXCHANGE HYPOTHESES A second theme in multidimensional analyses is the question of whether people trade characteristics when choosing a spouse. Several examples of exchange have been considered, but the most debated case was introduced by Davis (1941) and Merton (1941), who argued that members of ethnic groups whose prestige in society is low would have better chances of marrying outside their group if they offered a high socioeconomic status in return.

The Davis-Merton hypothesis is most frequently examined in research on ethnic and racial intermarriage. Loglinear and harmonic mean analyses of black-white intermarriage by Kalmijn (1993a) and Schoen \& Wooldredge (1989) show that with respect to education, white women marry up more often when marrying a black man than when marrying a white man; similarly, black men marry down more often when marrying a white woman than when marrying a black woman. Similar conclusions apply when examining the marriage choices of white men and black women. White men marry down less often when marrying exogenously and black women marry up less often in mixed marriages. These asymmetries in spouses' educational characteristics are assessed after controlling for the marginal educational distributions of race-sex groups and thereby support the hypothesis that majority men and women marry a minority spouse in part under the condition of socioeconomic status gains.

While the pattern of black-white marriage provides support for the DavisMerton hypothesis, studies of other types of ethnic homogamy are less consistent. In a harmonic mean analysis of Asian intermarriage in Hawaii, Schoen \& Thomas (1989) show that after controlling for differences in educational distributions, white women marry up more often when they marry Filipino and Japanese males, consistent with the notion of exchange. The reverse is true, however, when white women marry Hawaiian or Chinese males.

The exchange hypothesis has also been applied to other dimensions of partner choice, such as physical attractiveness and cultural participation. To examine exchanges, studies generally rely on correlational analyses in which socioeconomic characteristics of the husband are regressed on socioeconomic and noneconomic characteristics of the wife. Effects of the wife's noneconomic characteristics on the husband's socioeconomic characteristics are usually called crossing effects and are considered evidence for exchange.

In an early analysis of physical attractiveness of women and occupational prestige of men, Taylor \& Glenn (1976) show that female attractiveness has a positive effect on the occupational prestige of the man she marries, even when controlling for her own socioeconomic characteristics. A drawback of this 
analysis is that husband's attractiveness was not included in the model. If occupational prestige and attractiveness are correlated within individuals, and if people match in attractiveness, part of the effect of female attractiveness on male prestige may be spurious. A more recent analysis, which also controls for the physical attractiveness of the husband, confirms this. Stevens et al (1990) find no effect of female attractiveness on husbands' education, suggesting that no exchanges are being made.

Another example of exchange is that between socioeconomic status and participation in high culture. DiMaggio \& Mohr (1985) find that participation of the wife in high culture has a positive effect on the educational level of the husband, net of the educational level of the wife. Because no measures of the husband's cultural participation were included in this model, the exchange effect might again be due to homogamy with respect to cultural participation. An analysis for the Netherlands, however, shows that this is not the case. Uunk (1996) analyzes the correlation between the wife's cultural participation and the husband's educational level while controlling not only for the wife's educational level but also for the husband's cultural participation. Uunk finds a significant partial association between female high culture and male education, providing support for the exchange hypothesis.

\section{CONCLUSION}

Sociological research on marriage choices has generated many insights in how modern society is differentiated. In general, social groups in society appear closed, in the sense that men and women more often choose partners within their group than one would expect under random mating. Although some groups are more closed than others, examples of social groups who marry exogamously have not (yet) been found. Research on intermarriage also reveals how societies change. Overall, ascribed bases of group membership have become less important, while achieved bases of group membership, and especially those governed by education, have not lost salience. This is not to say that ascribed groups are mixing freely now. Ethnic, religious, and particularly racial boundaries still exist, but they are weaker than they used to be.

The focus of the literature has largely been descriptive. Researchers have scrutinized a mass of data - coming from censuses, surveys, and marriage licenses - and have studied many groups, several countries, and long periods of time. Because marriage patterns are telling indicators of how closed groups in a society are, the descriptive focus of the literature has much to say for it. Monitoring such a social indicator also requires a certain degree of standardization, and in this respect, the literature has its shortcomings. Some studies are limited to percentages, which are heavily affected by relative group size, making it difficult to compare endogamy across groups. Other studies use loglinear 
models, and while these are an advance from a methodological point of view, they have probably made the literature less accessible to a general audience than it deserves to be. In carrying on its descriptive mission, the literature would gain by using simple odds ratios next to percentages or loglinear models when describing the degree of endogamy of groups. A good example of such an approach is provided in Lieberson \& Waters (1988). In describing trends, it would also be useful to focus on recently formed marriages rather than on the stock of marriages at a given point in time, largely because the aim is to present social indicators for a clearly defined period in time.

In a theoretical sense, there has also been progress in the field. There are many theories about partner choice, and such notions provide important clues about the causes of intermarriage and homogamy. In general, marriage patterns arise from three social forces: the preferences of individuals for resources in a partner, the influence of the social group, and the constraints of the marriage market. The multifaceted perspective that has been developed over the years gives sociological theorizing an edge over competing theories of marriage choice such as those developed by psychologists and economists.

Considerable empirical evidence exists for these theoretical notions, but the integration of empirical and theoretical work is less than perfect. There are two basic problems in empirical work. First, many hypotheses are tested in an indirect fashion. The role of third-party control, for example, is documented by comparing ethnic groups or religious denominations, but little information is available on what these parties in fact are doing. Similarly, the trend towards increasing educational homogamy may point to heightened competition for economic resources on the marriage market, but this is an interpretation, not a test. A second and related problem in empirical work is that many of the observed regularities and relationships can be attributed to all three types of causes, while little is yet known about the relative strengths of these factors. That more highly educated members of minority groups are less endogamous, for example, may be attributed to a universalistic attitude brought about by higher education, but can also be explained in terms of greater opportunities to meet outgroup members. In a similar fashion, residential segregation may foster endogamy by lowering opportunities, but its effect may also be explained by different socialization practices in segregated areas.

While it is clear that progress can be made in integrating theoretical and empirical work, this is not a straightforward task either. One possible solution is to shift the focus from the aggregate to the individual level. In the past, most studies have compared countries, groups, or time periods, but few studies have analyzed individual differences in intermarriage. The main advantage of an individual approach is that it facilitates the inclusion of a range of covariates for each of the three elements of the theory. For example, one can focus on socialization practices and characteristics of the parental home to test hypotheses 
about third-party control. One can also include sex-role attitudes or expectations regarding paid and domestic labor later in life to examine the role of preferences. Finally, one can include contextual variables, such as characteristics of the settings in which young adults are embedded (schools, workplaces, neighborhoods) to assess the effects of local marriage markets on intermarriage.

While an individual design would facilitate the multivariate analyses that are needed to test hypotheses more directly and to compare the strength of alternative explanations, such a design has its problems as well. Because multivariate analyses of marriage choices use individuals as the unit of analysis, they provide a one-sided view of marriage. It takes two to marry, and for that reason most authors have used loglinear or harmonic mean models. Such models correctly use marriages as the unit of analysis, rather than individuals, but make it difficult to include multiple covariates in the model. From a methodological point of view, such models are preferable, but if the prime concern is to test theories, their advantage is not so obvious.

\section{Visit the Annual Reviews home page at http://www.AnnualReviews.org.}

\section{Literature Cited}

Alba RD. 1976. Social assimilation among American Catholic national-origin groups. Am. Sociol. Rev. 41:1030-46

Alba RD, Golden RM. 1986. Patterns of ethnic marriage in the United States. Soc. Forces 65:202-23

Anderson RN, Saenz R. 1994. Structural determinants of Mexican American intermarriage, 1975-1980. Soc. Sci. Q. 75: 414-30

Blau PM, Blum TC, Schwartz JE. 1982. Heterogeneity and intermarriage. Am. Sociol. Rev. 47:45-62

Blau PM, Duncan OD. 1967. The American Occupational Structure. New York: Wiley

Blau PM, Schwartz JE. 1984. Crosscutting Social Circles. London: Academic

Blossfeld H-P, Timm A. 1997. Der Einfluß des Bildungssystems auf den Heiratsmarkt: ein längsschnittanalyse der Wahl von Heiratspartnerern im Lebenslaub. Kölner $Z$. Soziol. Sozialpsychol. 49:440-76

Bozon M, Heran F. 1989. Finding a spouse: a survey of how French couples meet. Population 44:91-121
Byrne D. 1971. The Attraction Paradigm. New York: Academic

Davis FJ. 1991. Who Is Black? One Nation's Definition. University Park: Penn. State Univ. Press

Davis K. 1941. Intermarriage in caste societies. Am. Anthropol. 43:388-95

Davis K. 1984. Wives and work: consequences of the sex-role revolution. Popul. Dev. Rev. 10:397-417

DiMaggio P, Mohr J. 1985. Cultural capital, educational attainment, and marital selection. Am. J. Sociol. 90:1231-61

Drachsler J. 1920. Democracy and Assimilation: The Blending of Immigrant Heritages in America. New York: Macmillan

Eschbach K. 1995. The enduring and vanishing American Indian: American Indian population growth and intermarriage in 1990. Ethn. Racial Stud. 18:89-108

Forsé M, Chauvel L. 1995. L'évolution de l'homogamie en France. Rev. Fr. Sociol. 36:123-42

Gilbertson GA, Fitzpatrick JP, Lijun Y. 1996. Hispanic intermarriage in New York City: 
new evidence from 1991. Int. Migr. Rev. 30:445-59

Glass D. 1954. Social Mobility in Britain. London: Routledge \& Kegan Paul

Glenn ND. 1982. Interreligious marriage in the United States: patterns and recent trends. J. Marriage Fam. 44:555-66

Gordon MM. 1964. Assimilation in American Life. New York: Oxford Univ. Press

Gurak DT, Fitzpatrick JP. 1982. Intermarriage among Hispanic groups in New York City. Am. J. Sociol. 87:921-34

Hayes BC. 1991. Religious identification and marriage patterns in Australia. J. Sci. Study Relig. 30:469-78

Hayes BC. 1993. Occupational homogamy within Northern Ireland and the Republic of Ireland: a loglinear analysis. Int. J. Sociol. Soc. Policy 13:99-117

Hendrickx J. 1994. The analysis of religious assortative mating: an application of design techniques for categorical models. $\mathrm{PhD}$ thesis. Nijmegen Univ., Netherlands. $312 \mathrm{pp}$.

Hendrickx J, Lammers J, Ultee WC. 1991. Religious assortative marriage in the Netherlands, 1938-1983. Rev. Relig. Res. 33: $123-45$

Hendrickx J, Schreuder O, Ultee WC. 1994. Die konfessionelle Mischehe in Deutschland (1901-1986) und den Niederlanden (1914-1986). Kölner Z. Soziol. Sozialpsychol. 46:619-45

Hout M. 1982. The association between husbands' and wives' occupations in twoearner families. Am. J. Sociol. 88:397-409

Hwang SS, Saenz R, Aguirre BE. 1994. Structural and individual determinants of outmarriage among Chinese, Filipino, and Japanese Americans in California. Sociol. Inq. 64:396-414

Hwang SS, Saenz R, Aguirre BE. 1995. The SES-selectivity of interracially married Asians. Int. Migr. Rev. 29:469-91

Jacobs JJ, Furstenberg FF. 1986. Changing places, conjugal careers, and women's marital mobility. Soc. Forces 64:714-32

Jiobu RM. 1988. Ethnicity and Assimilation. Albany: State Univ. NY Press

Johnson RA. 1980. Religious Assortative Marriage in the United States. New York: Academic

Jones FL. 1987. Marriage patterns and the stratification system: trends in educational homogamy since the 1930s. Aust. NZJ. Sociol. 23:185-98

Jones FL, Davis P. 1988. Class structuration and patterns of social closure in Australia and New Zealand. Sociology 22:271-91

Jones FL, Luijkx R. 1996. Post-war patterns of intermarriage in Australia: the Mediterra- nean experience. Eur. Sociol. Rev. 12: 67-86

Kalmijn M. 1991a. Status homogamy in the United States. Am. J. Sociol. 97:496-523

Kalmijn M. 1991b. Shifting boundaries: trends in religious and educational homogamy. Am. Sociol. Rev. 56:786-800

Kalmijn M. 1993a. Spouse selection among the children of European immigrants: a comparison of marriage cohorts in the 1960 census. Int. Migr. Rev. 27:51-78

Kalmijn M. 1993b. Trends in black/white intermarriage. Soc. Forces 72:119-46

Kalmijn M. 1994. Assortative mating by cultural and economic occupational status. Am. J. Sociol. 100:422-52

Kennedy RJR. 1944. Single or triple melting pot? Intermarriage trends in New Haven, 1870-1940. Am. J. Sociol. 49:331-39

Klein T, Wunder E. 1996. Regionale Disparitaten und Konfessionswechsel als Ursache konfessioneller Homogamie. Kölner Z. Soziol. Sozialpsychol. 48:96-125

Kosmin BA, Goldstein S, Waksberg J, Lerer N, Keysar A, Scheckner J. 1991. Highlights of the 1990 National Jewish Population Survey. New York: Counc. Jewish Fed.

Lazerwitz B. 1995. Jewish-Christian marriages and conversions, 1971 and 1990. Sociol. Relig. 56:433-43

Lee SM, Yamanaka K. 1990. Patterns of Asian American intermarriage and marital assimilation. J. Comp. Fam. Stud. 21: 287-305

Lieberson S. 1980. A Piece of the Pie: Blacks and White Immigrants Since 1880. Berkeley: Univ. Calif. Press

Lieberson S, Waters MC. 1988. From Many Strands: Ethnic and Racial Groups in Contemporary America. New York: Russell Sage Found.

Mare RD. 1991. Five decades of educational assortative mating. Am. Sociol. Rev. 56: 15-32

McCutcheon AL. 1988. Denominations and religious intermarriage: trends among white Americans in the twentieth century. Rev. Relig. Res. 29:213-27

Merton RK. 1941. Intermarriage and the social structure. Psychiatry 4:361-74

Morgan BS. 1981. A contribution to the debate on homogamy, propinquity, and segregation. J. Marriage Fam. 43:909-21

Murstein BI. 1976. Who Will Marry Whom: Theories and Research in Marital Choice. New York: Springer

Pagnini DL, Morgan PS. 1990. Intermarriage and social distance among U.S. immigrants at the turn of the century. Am. J. Sociol. 96:405-32 
Peach C. 1974. Homogamy, propinquity, and segregation: a re-evaluation. Am. Sociol. Rev. 39:636-41

Qian Z. 1997. Breaking the racial barriers: variations in interracial marriage between 1980 and 1990. Demography 34:263-76

Ramsøy NR. 1966. Assortative mating and the structure of cities. Am. Sociol. Rev. 31: $773-86$

Sandefur GD, McKinnell T. 1986. American Indian intermarriage. Soc. Sci. Res. 15: 347-71

Schoen R. 1988. Modeling Multigroup Populations. New York: Plenum

Schoen R, Thomas B. 1989. Intergroup marriage in Hawaii, 1969-1971 and 19791981. Sociol. Perspect. 32:365-82

Schoen R, Thomas B. 1990. Religious intermarriage in Switzerland, 1969-72 and 1979-82. Eur. J. Popul. 6:359-76

Schoen R, Wooldredge J. 1989. Marriage choices in North Carolina and Virginia, 1969-71 and 1979-81. J. Marriage Fam. 51:465-81

Smits J, Ultee W, Lammers J. 1998. Educational homogamy in 65 countries: the explanation of differences in openness with country-level explanatory variables. $\mathrm{Am}$. Sociol. Rev. In press

Snipp CM. 1989. American Judians: the first of this land. New York: Russell Sage

Stevens G, Owens D, Schaefer EC. 1990. Education and attractiveness in marriage choices. Soc. Psychol. Q. 53:62-70

Sung BL. 1990. Chinese American intermarriage. J. Comp. Fam. Stud. 21:337-52

Sweet JA, Bumpass LL. 1987. American Families and Households. New York: Russell Sage

Taylor PA, Glenn ND. 1976. The utility of education and attractiveness for females' status attainment through marriage. Am. Sociol. Rev. 41:484-98

Ultee WC, Luijkx R. 1990. Educational heterogamy and father to son occupational mobility in 23 industrial nations: general societal openness or compensatory strategies of reproduction? Eur. Sociol. Rev. 6: 125-49

US Bureau of the Census. 1985. Marital characteristics. 1980 Census of Population, Subject Report, PC80-2-4C. Washington, DC: US Gov. Printing Off.

Uunk WJG. 1996. Who marries whom? The role of social origins, education and high culture in mate selection of industrial societies during the twentieth century. $\mathrm{PhD}$ thesis. Nijmegen Univ., Netherlands. 181 pp.

Uunk WJG, Ganzeboom HBG, Róbert P. 1996. Bivariate and multivariate scaled association models: an application to homogamy of social origin and education in Hungary between 1930 and 1979. Qual. Quant. 30:323-43

Uunk WJG, Kalmijn M. 1996. Wie trouwt met wie binnen de opleidingselite: de invloed van studierichting en onderwijsniveau. Sociol. Gids 43:183-200

Warren BL. 1966. A multiple variable approach to the assortative mating phenomenon. Eugen. Q. 13:285-90

Winch RF. 1958. Mate Selection: A Study of Complementary Needs. New York: Harper

Wirth L, Goldhamer H. 1944. The hybrid and the problem of miscegenation. In Characteristics of the American Negro, ed. O Klineberg, pp. 251-369. New York: Harper

Wong MG. 1989. A look at intermarriage among the Chinese in the United States in 1980. Sociol. Perspect. 32:87-107 


\section{CONTENTS}

Social Capital: Its Origins and Applications in Modern Sociology, Alejandro Portes

Fundamentalism Et Al: Conservative Protestants in America, Robert D. Woodberry, Christian S. Smith

Network Forms of Organizations, Joel M. Podolny, Karen L. Page

Reactions Toward the New Minorities of Western Europe, Thomas F.

Social Memory Studies: From "Collective Memory" to the Historical

Sociology of Mnemonic Practices, Jeffrey K. Olick, Joyce Robbins

Computerization of the Workplace, Beverly H. Burris

Globalization and Democracy, Kathleen C. Schwartzman

Social Dilemmas: The Anatomy of Cooperation, Peter Kollock 183

Breakdown Theories of Collective Action, Bert Useem 215

Warmer and More Social: Recent Developments in Cognitive Social 239

Diffusion in Organizations and Social Movements: From Hybrid Corn to

Poison Pills, David Strang, Sarah A. Soule

Alcohol, Drugs, and Violence, Robert Nash Parker, Kathleen Auerhahn

Commensuration as a Social Process, Wendy Nelson Espeland, Mitchell

L. Stevens

Measuring Meaning Structures, John W. Mohr

Was It Worth the Effort? The Outcomes and Consequences of Social

Movements, Marco G. Giugni

Intermarriageand Homogamy: Causes, Patterns, and Trends, Matthijs

Kalmijn

Ethnic and Nationalist Violence, Rogers Brubaker, David D. Laitin

Contemporary Developments in Sociological Theory, Charles Camic, Neil Gross

Using Computers To Analyze Ethnographic Field Data: Theoretical and Practical Considerations, Daniel Dohan, Martín Sánchez-Jankowski 